\title{
Birds and bees and neuronal circuits
}

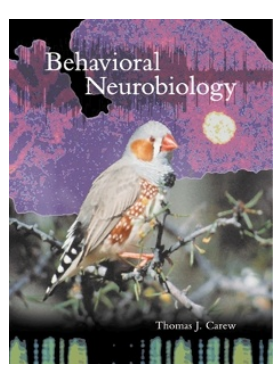

\section{Behavioral Neurobiology: The Cellular Organization of Natural Behavior}

I looked forward to reading this book. It is a series of stories on some of my favorite topics, written by Tom Carew, a talented teacher and erudite scholar. It turned out to be very lively and uplifting, but not as carefully crafted as I expected. Behavioral Neurobiology is a very timely work because it celebrates some of the most successful neuronal explanations of animal behaviors, a discipline that should become more important in the post-genomic era. Mutations, after all, are ultimately tested by their effects on the viability and behavior of the organism, so that knowing the cellular and molecular bases of behaviors should help us to understand how all those newly sequenced genes influence behaviors. This book is mainly about neuroethology, the study of the neural basis of natural behaviors (that is, those very behaviors that have been shaped by natural selection), although the final three chapters owe more to other traditions, mainly psychology, neurophysiology and molecular genetics. It springs from a very popular course that Tom developed at Yale over some 17 years. He maintains in the preface that, although this text is mainly intended for non-science majors, the format makes it useful for Biology majors and even graduate students. How can that be? Mainly this is done by being a 'readings in neurobiology' book, which tells intriguing stories about the behaviors of bats, owls, crickets, toads, locusts, crayfish, songbirds, honeybees, Aplysia, fruit flies and rats, rather than attempting to cover all topics in behavioral neurobiology. In this format, general principles emerge from discussions of the neuronal bases of the various behaviors rather than being stated up front. In addition, there are 'codas' at the ends of the three

Bill Kristan is at the University of California at San Diego, Section of Neurobiology, Division of Biological Sciences, 9500 Gilman Drive, La Jolla, California, 92093-0357, USA.

e-mail:wkristan@ucsd.edu major sections (Sensory Worlds, Motor Strategies and Behavioral Plasticity) that pull out the common themes of these sections. The 'start-from-behavior' approach of each chapter and the inherent interest in how animals work will appeal to the non-majors, and the detailed discussions of the neural bases of these behaviors should appeal to the advanced students. Does it work as a textbook? As a readings book? The answers are complicated, and depend upon balancing the book's strengths and weaknesses.

The strengths are considerable. First, a more current textbook on neuroethology is needed. Previous ones (for example, by Ewert, Guthrie and Camhi) were all written in the early 1980s. More recent texts by Reichert (Introduction to Neurobiology, Thieme, 1992) and Delcomyn (Fundamentals of Neurobiology, Freeman, 1997) have a comparative and behavioral perspective, but they use the more standard textbook approach that builds from ionic mechanisms to complex behaviors in incremental steps. Second, the chapters are serious, substantive presentations; there are no 'just so' stories in this book. Third, the introductions to the chapters, placing the animals to be discussed in a biological perspective, are graceful, informative and set a good tone for discussing each animal's behavior. Fourth, the topics are structured around key experiments; most chapters start with the description of some behavior and proceed through a series of experiments to determine how the animal's nervous system produces that behavior. The chapters often give a good sense of how research actually progresses. Fifth, much of the introductory material in the first chapter is first rate and not found in any other text. In particular, the discussion of necessity and sufficiency (what these terms mean and why they are important weapons in the scientific arsenal) is superb. It deserves to be repeated in every textbook of neurobiology. Sixth, some of the chapters are outstanding: the review of Drosophila neurogenetics and of spatial navigation in rats are the best I've seen on these topics, and the Aplysia work is nicely reviewed. Finally, Carew relates all the material with great enthusiasm and verve. He captures the feeling that we all get when we finally figure something out. At its best, this book makes research seem both accessible and exciting.

The weaknesses of the book, alas, are also substantial. For instance, having established most of the introductory concepts nicely, they are hardly ever mentioned again. There are innumerable missed opportunities to say things like, "See, this is a perfect example of proving sufficiency." In addition, several chapters (for example, the second chapter, on echolocation in bats) mention concepts that are explained only in later chapters, and many of the topics are presented in a historical order, rather than a logical one. It would be more effective to hammer home the major themes and general principles as they are presented, rather than depending entirely upon a coda every three or four chapters to highlight the generalities. Also, the style is chatty, with a number of irreverent (and distracting) asides. These devices can often work well in a lecture, to maintain audience interest, but they sometimes fall flat when written out. The text also suffers from several other problems. For example, terms are used without definition, but then are defined paragraphs later, or a term is defined, but then a synonym is used in its place. Many figures are either needlessly cluttered or not well explained; difficult concepts (like the propagation of sound waves and phase-locking of spikes) are described vaguely in words when a figure would easily clarify the matter. Finally, many of the chapters are out of date, several being over five years behind the times (although the final three chapters are notable exceptions).

Is it a good read? Yes and no. I learned something in every chapter and much in some chapters, but I also grumbled a lot as I marked errors, problems or wrote out suggestions for improvement in the margins. Is it a good textbook? I teach part of a course in neurobiology and behavior to non-majors, and I was hoping that this would be an appropriate text. We will try it out, but I fear that the style may be too idiosyncratic, and some of the presentations too confusing. Hopefully, a second edition-updated and tightened up — will be the ideal one. 